\title{
Balpeteği Sandviç Kompozitlerin Treyler Ön Panellerine Uygulanabilirliğinin Sonlu Elemanlar Analizi ile İncelemesi
}

\author{
Miraç Mutlu1 ${ }^{*}$, Ayşegül Akdoğan Eker2², Emin Emre Göktepe ${ }^{3}$, \\ 1* * Makine Mühendisliği Bölümü / Makine Enstitüsü, Yıldız Teknik Üniversitesi, İstanbul, Türkiye, (ORCID: 0000-0002-0048-0361), mirac.mutlu@tirsan.com \\ 2 Makine Mühendisliği Bölümü / Makine Enstitüsü, Yıldız Teknik Üniversitesi, İstanbul, Türkiye, (ORCID: 0000-0003-0212-9230), aysegul@yildiz.edu.tr \\ 3 Tirsan Treyler San. ve Tic. A.Ş, Sakarya, Türkiye, (ORCID: 0000-0003-0292-578X), emre.goktepe@kaessbohrer.com
}

(2nd International Conference on Applied Engineering and Natural Sciences ICAENS 2022, March 10-13, 2022)

(DOI: 10.31590 /ejosat.1081516)

ATIF/REFERENCE: Mutlu, M., Akdoğan, Eker, A., Göktepe, E. E., (2022). Balpeteği Sandviç Kompozitlerin Treyler Ön Panellerine Uygulanabilirliğinin Sonlu Elemanlar Analizi ile İncelemesi. European Journal of Science and Technology, (34), 285-291.

$\ddot{O} z$

$\mathrm{Bu}$ çalışmada, tenteli perdeli treyler ön panellerine balpeteği sandviç kompozitlerin uygulanabilirliği sonlu elemanlar analizi (FEA) ile incelenmiş̧ir. Balpeteği sandviç yapılı kompozitlerden; polipropilen (PP) balpeteği, S320 çelik levha ve 3005 H19 alüminyum alaşımı balpeteği, $5457 \mathrm{H} 22$ alüminyum levhalardan imal edilmiş iki farklı kompozit bu çalışmanın kapsamında değerlendirilmiştir. TS EN 12642 normunda belirtilen test standartları göz önüne alınarak statik analizler gerçekleştirilmiştir. Kompozit malzemelere uygulanan analizlerde gerilme dağılımı, toplam deformasyon ve gerinim enerjisi çıktıları değerlendirilmiştir. Analizler sonucunda, PP balpeteği kompozit ön panelde en yüksek gerilme değeri $2439 \mathrm{MPa}$, deplasman $68 \mathrm{~mm}$ ve gerinim enerjisi $3108 \mathrm{~mJ}$ olarak elde edilmiştir. Alüminyum balpeteği kompozit ön panelde ise en yüksek gerilme değeri $391 \mathrm{MPa}$, deplasman değeri $29 \mathrm{~mm}$ ve gerinim enerjisi 286 mJ olarak bulunmuştur. Elde edilen veriler göz önüne alındığında, polipropilen balpeteği yapılı kompozit ön panel için gerekli özellikleri sağlayamadığı, alüminyum balpeteği yapılı kompozitlerin ise uygulanabilir olduğu sonucuna varılmıştır.

Anahtar Kelimeler: Treyler, Kompozit, Balpeteği, Ön Panel, Sonlu Elemanlar Analizi (FEA).

\section{Investigation of the Applicability of Honeycomb Sandwich Composites to Trailer Front Panels by Finite Element Analysis}

\begin{abstract}
In this study, the feasibilty of honeycomb sandwich composites to curtainsider trailer bulkhead was investigated by finite element analysis (FEA). Honeycomb sandwich composites: two different composites made of polypropylene (PP) honeycomb, S320 steel skin and 3005 H19 aluminum alloy honeycomb, 5457 H22 aluminum skin were evaluated within the scope of this study. Static analyzes were carried out considering the test standards specified in the TS EN 12642 norm. Stress distribution, total deformation and strain energy outputs were evaluated in the analyzes applied to composite materials. As a result of the analysis, the highest stress value was obtained as $2439 \mathrm{MPa}$, displacement $68 \mathrm{~mm}$ and strain energy $3108 \mathrm{~mJ}$ in the PP honeycomb composite front panel. In the aluminum honeycomb composite front panel, the highest stress value was found to be $391 \mathrm{MPa}$, the displacement value was $29 \mathrm{~mm}$, and the strain energy was $286 \mathrm{~mJ}$. Considering the data obtained, it was concluded that polypropylene honeycomb composite front panel could not provide the necessary properties, while aluminum honeycomb composites were applicable
\end{abstract}

Keywords: Trailer, Composite, Honeycomb, Bulkhead, Finite Element Analysis (FEA).

\footnotetext{
* Corresponding Author: mirac.mutlu@tirsan.com
} 


\section{Giriş}

Günümüzde taşımacılık sektörü her geçen gün yapılan yatırımlar ve araştırmalar sayesinde büyümektedir. İnsan hayatı için önem arz eden bir yerde bulunan bu sektörünün \%75'lik kısmını ise karayolları taşımacılığı oluşturmaktadır. (Schellens) Kara yolları taşımacılığı hızlı operasyonlar sağlayabilmesi, finansal açıdan uygunluğu gibi pek çok avanta sahiptir. Kara yolları taşımacılığında en yaygın kullanılan taşıma araçları ise yarı römorklar olarak da adlandırılan treylerlerdir. Treyler, bir kısmı motorlu taşıt veya araç üzerine oturan, taşıdığı yükün ve kendi ağırlığının bir kısmı motorlu araç tarafından taşınan römorklardır. (Karayolları Genel Müdürlüğü, 2022) Taşıdıkları yükün niteliğine bağlı olarak pek çok çeşidi bulunan treylerler akaryakıt, gıda, kuru yük, tekstil endüstrisi gibi pek çok alanın ihtiyaçlarını karşılayabilmektedirler. Treylerler taşıdıkları yüklerin cinslerine ve konstrüksiyonlarına bağlı olarak kendi içlerinde özel isimlendirilmişlerdir. Örnek olarak Şekil 1'de gösterilen tenteli perdeli treylerler üstyapıları; ön panel ve arka kapıdan oluşan, aracın yan ve üst kısmının perde ile kapatılmış olan bir treyler tipidir. Tenteli perdeli araçlar genellikle kuru yük taşımacılığında tercih edilmesine karşın depolanmış sıvılar (ör. şişe suları vb.) taşıyabilmesi yönünden geniş ürün yelpazesine hitap etmektedirler. Bu avantajları sayesinde de kendisini treyler pazarındaki en büyük paya sahip treyler çeşidi yapmaktadır.

Treylerlerin, çeşitli uluslararası ve yurt içi yönetmeliklerin denetimleri altında karayollarında kullanılmalarına izin verilmektedir. Karayolları Trafik Yönetmeliği'nin 128.maddesine göre araçların boyu, ağırlıkları ve aynı yönetmeliğin 134.maddesinde yer alan yüklenme koşulları vb. çeşitli tasarımsal, yükleme vb. sınırlandırmalarına ve gereksinimlere tabii tutulmaktadırlar.

Treyler üreticileri, taşımacılık yönetmelikleri gereksinimlerine uyarak pazarda kendilerine pay bulabilmek adına müşteriler için en uygun treyleri üretilmesine çalışmaktadırlar.

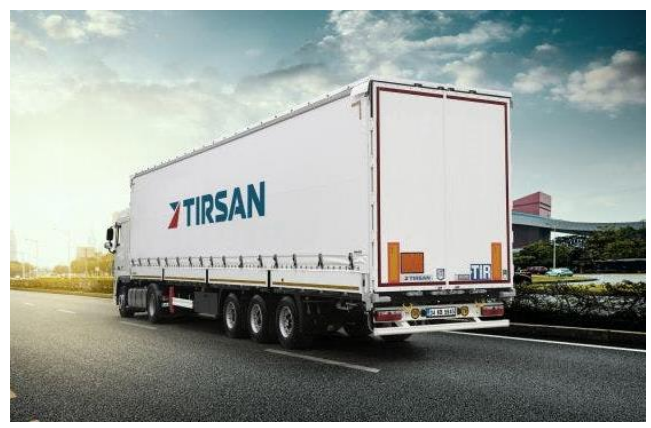

Şekil 1. Tenteli Perdeli Treyler (Tirsan, 2022)

Çalışma kapsamında incelenen tenteli perdeli treylerler ön panelleri için çeşitli yük emniyeti sertifikasyonları bulunmaktadır. Ülkemizde ve Avrupa'da kabul görülen TS EN 12642 (Türk Standartlar Enstitüsü,2016) treyler sertifikasyonları arasında gövde yapılarını kapsamaktadır TS EN 12642 sertifikasyonu treylerlerin tüm gövde yapılarının asgari koşullarını ve sertifikasyon için uygulanması gereken test parametrelerini belirtmektedir. Temel olarak ön panellere uygulanan testler statik ve dinamik olarak iki başlık altında gerçekleştirilmektedir. Ön panellerin sertifikasyonunun tamamlanması için her iki testten de başarılı olmaları gerekmektedir.
Rekabetin yüksek olduğu treyler pazarında; minimum net araç ağırlığı, maksimum iç hacim ve birden fazla fonksiyona sahip bir araç olma özelliğinin gerçekleştirilebilmesi (Schellens) araçların diğer alternatiflerinden ayrılmasını sağlamaktadır. Otomotiv sektöründe malzeme açısından kompozitlerin kullanımı ön plana çıkmaktadır.

Kompozitler yüksek dayanım-ağırlık oranı, termal izolasyon olarak kullanılabilmeleri, yüksek enerji sönüm kapasiteleri ve yüksek çeşitliliğe sahip olmaları gibi özelliklerinden dolayı konvansiyonel malzemelerin yerine otomotiv sektöründe yaygın kullanılmaya başlanmış ve üzerine pek çok akademik çalışma yapılmıştır. (Zinno, 2011), (Gao, 2020) H. Schellens arkadaşları (Schellens) yaptıkları çalışmasında, sandviç kompozit paneller ile treyler tasarımı üzerine çalışmış, maliyette ciddi artışlara sebebiyet vermeden, aracın taşıma yükünün ve fonksiyonelliğinin arttırılabileceği sonucuna varmıştır. J. Galos, (Hou, 2022) treyler tabanlarında genellikle ahşap olarak tercih edilen döşemelerin sandviç kompozit alternatiflerini değerlendirmiştir.
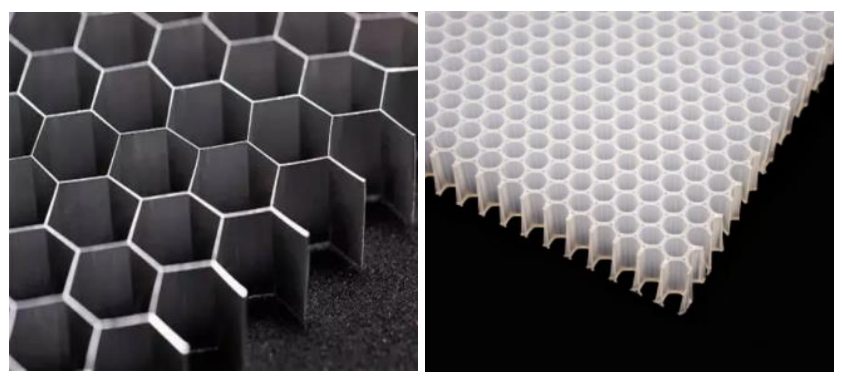

Şekil 2. Sol Alüminyum (Pentour Honeycomb Online Store, 2022), Să̆ Poliptopilen (Made-in-China, 2022) Balpeteği

Yapılan literatür çalışmasında balpeteği sandviç yapılı kompozitler akademik ve sektörel çevrede üzerine yoğunlaşılan, önemli bir alan olduğu görünmektedir. Balpeteğinin yapısı ve malzemesindeki çeşitlilik, levha olarak hem konvansiyonel hem ileri teknoloji malzemelerinin kullanılabilmesi, hafiflik ve bu özelliğe bağl1 CO2 emisyonunda azalması, bu tip kompozitlerde istenilen özelliklerin bir arada bulunmasını sağlamaktadır. Otomotivde kullanılan balpeteği kompozitler üzerine çokça çalışmıştır: 2011 yılında A. Zinno, (Zinno, 2011) ulaşım araçları için fenolik emdirilmiş balpeteği sandviç yapıların deneysel karakterizasyonu gerçekleştirmiş, çevresel faktör etkileri ve dezavantajları en aza dindirebilmek üzere tasarım parametrelerine değinmiştir. 2020 yılında X. Gao, (Gao, 2020) otomotiv ve inşaat sektörlerinde kullanılan termoplastik balpeteği sandviç kompotitlerin eğilme yükü altında deneysel, sonlu elemanlar analizi verilerini karşılaştırmıştır. W. Hou, (Hou, 2022) karbon fiber balpeteği kompozitlerin motor kaputu tasarımında uygulanması üzerine çalışmış referans alınan alüminyum alaşımlı motor kaputu yapısı ile karşılaştırıldığında, daha iyi sertlik performans1 koşuluyla optimal yapının ağırlığ $1 \% 61,8$ azaltılmasını sağlamıştır.

Balpeteği yapıları üretildikleri malzemelerin özelliklerini taşısalar dahi yapısal tasarımları gereğince izotropik olan malzemelere ortotropik özellikleri kazandırmaktadırlar. Temelde ortotropik malzemelerin dokuz adet elastiklik sabiti bulunmaktadır. Çeşitli çalışmalarda mühendislik sabitleri olarak da adlandırılan Elastiklik Modülü (E), Poisson Oran (v) Kayma Modülü (G) kullanılmakta olup bu sabitler uzaydaki koordinatlarına bağlı olarak değişiklik gösterdiklerinden dolayı kendi içerlerinde varyasyonlara sahiplerdir. $\mathrm{Bu}$ sabitler: $E_{1}, E_{2}$, $E_{3}, v_{12}, v_{13}, v_{23}, G_{12}, G_{13}, G_{23}$ olarak simgesel olarak 
nitelendirilmektedirler. Mühendislik sabitlerinin sayısal hesaplanmasını araştırılam pek çok çalışmalar vardır, ancak bir balpeteği malzemesi için dokuz elastik sabitin tamamını veren bir çalışma bulmak zordur. (Andrew, 2022) Literatürde konuyla ilgili çok farklı çalışmalar bulunmasına karşın, malzeme özelliklerinin belirlenebilmesi adına yapılan hesaplamalar benzer teorilere dayanmaktadır. $\mathrm{Bu}$ analitik hesaplamalarda sürekli formülasyonlar ve malzemenin mukavemetine dayalı çeşitli kiriş teorileri içeren modellemeler esas alınarak yapılmaktadır. (Aydıncak, 2007) Ortotropik malzemelerin mühendislik sabitlerinin analitik hesaplanması üzerine; Kelsey (Kelsey, 1958), Master ve Evans (Masters ve Evans, 1996), Zhang ve Ashby (Zhang ve Ashby, 1992), Qunli Liu (Liu, 2007) Jones and Burgess (Jones and Burgess, 1979) ve E. Nast (Nast, 1997) araştırmacıların çalışmaları bulunmaktadır.

Balpeteği Sandviç Kompozitlerin Treyler Ön Panellerine Uygulanabilirliğinin Sonlu Elemanlar Analizi ile İncelemesi adlı çalışmamızda, ön panellerde mevcut durumda kullanılan konvansiyonel alüminyum malzemenin yerine, mukavemeti daha yüksek, gelen yükleri absorbe edip plastik deformasyona uğramayan, daha hafif bir balpeteği kompozit uygulanması hedeflenmektedir. $\mathrm{Bu}$ istenilen geliştirmeler sayesinde komponentin genel yapısında mukavimlik, darbe dayanımı yüksek, hafif, yakıt tüketimini ve $\mathrm{CO} 2 \mathrm{vb}$. zehirli gaz salınımının azalmasını sağlanmış olacaktır.

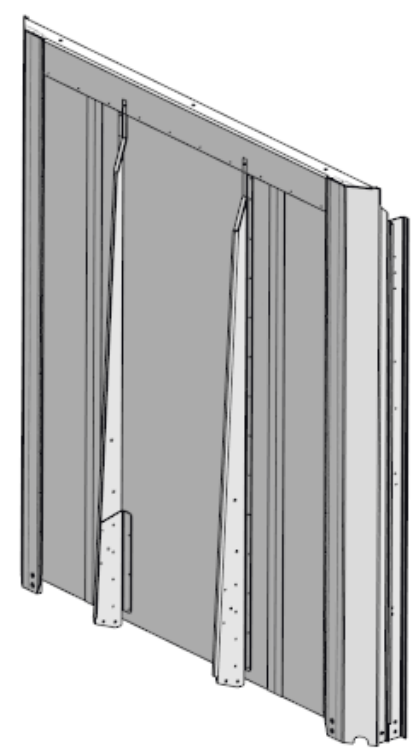

Şekil 3. 3D Modellenmiş Kompozit Ön Panel Komplesi

\section{Materyal ve Metot}

Çalışmada, iki farklı çekirdek ve levha yapısına sahip balpeteği sandviç kompozitinin treyler ön panellerine uygulanabilirliği incelenmiştir. Balpeteği yapılarının elastiklik davranışlarının belirlenmesi için sayısal hesaplamalar yapılmıştır. Aynı özellikler ANSYS programının "Material Designer" modülünden de hesaplanarak doğrulanmıştır. Malzemelerin treyler ön paneline basitleştirilmiş Şekil 3'de gösterilen 3D modellemeleri Creo Parametrik uygulamasında gerçekleştirilmiştir. Son olarak ise elde edilen tüm veriler kullanılarak ANSYS programın "Static Structual” modülünde statik analizleri gerçekleştirilmiştir.

\subsection{Balpeteği Sandviç Kompozit}

İncelenen farklı iki kompozit, polipropilen balpeteği, S320 çelik levhadan ve $3005 \mathrm{H} 19$ alüminyum $0,005 \mathrm{~mm}$ folyodan üretilmiş balpeteği, 5457 H22 alüminyum sac levhadan imal edilmişlerdir. Şekil 4'te balpeteklerinin geometrik özellikleri; hücre kenar uzunluğu a, hücre genişliğine d, hücre kalınlığın t, ve balpeteği içi açısı $\varphi$ açısı gösterilmiş ve çalışmada incelenen balpeteklerinin geometrik değerleri Tablo 1'de verilmiştir.

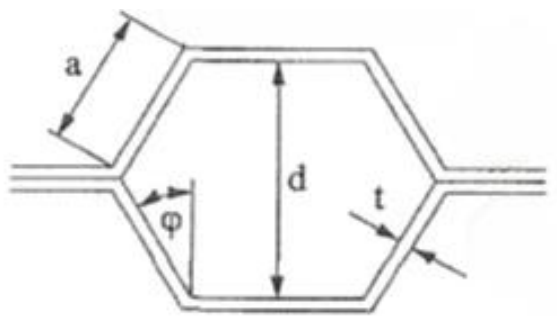

Şekil 4. Altıgen Balpeteği Geometrik Yapısı (Andrew, 2022)

Tablo 1. Polipropilen ve Alüminyum Balpeteklerin Geometrik Ölçüleri

\begin{tabular}{|c|c|c|c|c|}
\hline Balpeteği & $\mathbf{a}(\mathbf{m m})$ & $\mathbf{d}(\mathbf{m m})$ & $\mathbf{t}(\mathbf{m m})$ & $\boldsymbol{\varphi}\left(^{\circ}\right)$ \\
\hline Polipropilen & 5,77 & 9,8 & 0,4 & 30 \\
\hline Alüminyum & 5,65 & 10,39 & 0,05 & 30 \\
\hline
\end{tabular}

\subsection{Ototropik Malzemelerin Elastiklik Sabitlerinin Sayısal Hesaplanması}

Kompozit bileşenlerinden yüzeylerin izotropik özellikler gösterdiklerinden ötürü modellenmeleri malzemenin elastiklik sabitlerine bağlıdır. Balpeteği yapılar ise ortotropik özellikler göstermektedirler. $\mathrm{Bu}$ özelliklerinden ötürü balpeteklerinin gösterdiği tepki sadece malzemenin özelliklerine değil aynı zamanda çekirdek yoğunluğunun, çekirdeği oluşturan malzemenin yoğunluğuna olan oranına (Zinno, 2011) da bağlıdır. Çalışmada; $E_{1}, E_{2}, E_{3}, v_{12}, G_{12}$ hesaplamaları için Master ve Evans'ın (Masters ve Evans, 1996), $v_{23}, v_{13}, G_{23}$ hesaplamarı için Zhang and Ashby (Zhang ve Ashby, 1992), ve $G_{13}$ hesaplaması için Quinli'nin (Liu, 2007) geliştirmiş oldukları sayısal hesaplama formülleri kullanılmıştır ve geliştirilen denklemler aşağıda verilmiştir.

$$
\begin{aligned}
& E_{1}=\frac{E}{\frac{\cos \varphi}{(1+\sin \varphi)} *\left[\frac{\cos ^{2} \varphi * a^{3}}{t^{3}}+\frac{\left(2+\sin ^{2} \varphi\right) * t}{a}\right]} \\
& E_{2}=\frac{E}{\frac{(1+\sin \varphi)}{\cos \varphi} *\left[\frac{\sin ^{2} \varphi * a^{3}}{t^{3}}+\frac{\cos ^{2} \varphi * t}{a}\right]} \\
& E_{3}=E * \frac{t}{a}
\end{aligned}
$$




$$
\begin{aligned}
& v_{12}=\frac{\sin \varphi *(1+\sin \varphi)}{\cos ^{2} \varphi} \\
& G_{12}=\frac{G}{\frac{3 * \cos \varphi}{(1+\sin \varphi)} * \frac{a^{3}}{t^{2}}+[\cos \varphi+a * \tan \varphi *(1+\sin \varphi)] * \frac{a}{t}} \\
& G_{23}=\frac{\cos \varphi}{(1+\sin \varphi)} * \frac{t}{a} * G \\
& G_{13}=\frac{(1+\sin \varphi)}{2 * \cos \varphi} * \frac{t}{a} * G
\end{aligned}
$$

\subsection{Ototropik Malzemelerin Elastiklik Sabitlerinin Sonlu Elemanlar Analizi (FEA) ile Hesaplanması}

Balpeteği çekirdek yapısına sahip olan kompozitlerin bilgisayar analizlerinde modellenmesi oldukça karmaşık yapılar oluşturduklarından dolayı, kompozitlerin sürekli modelleme tercih edilmektedir. Bu tip modellemelerde tek tabakadan oluşan, yekpare bir yapı olarak gözüken model kullanılmaktadır. Yani başka bir değişle, karmaşı hücresel geometriyi bir dizi etkili süreklilik özelliğine dönüştürür. Oluşturulan model direkt olarak balpeteği yapının yerini alacağından yapılan hesaplamalar analiz sonuçlarının deneysel değerlerle eş olabilmesi adına kritik önem taşımaktadırlar.

$\mathrm{Bu}$ çalışmada ortotropik malzemelerin elastiklik sabitlerinin elde edilebilmesi için ANSYS programının "Material Designer" modülü kullanılmıştır. Material Designer modülünde temsili hacim öğesi (RVE) bulunmaktadır. Modül oluşturulan modele atanan izotropik malzemenin çeşitli yüklemeler altında gösterdiği tepkileri sonlu elemanlar yöntemi ile analiz eder. Elde ettiği sonuçlardan oluşturulan modelin malzemesini temsil eden, ortotropik elastik sabitlerinin hesaplanmasını sağlar. Ayrıca, bu elde edilen verilerle program içerisinde özel bir malzeme atanması da sağlanabilmektedir.

Material Designer modülü içerisinde balpeteği model için girdi olarak; balpeteğini oluşturan malzemenin izotropik özellikleri, balpeteği hücre kalınlığı $\mathrm{t}$, hücre kenar uzunluğu a, hücre iç açısı $\varphi$, ve hücre boyu girilmesi gerekmektedir. Tüm değerler girildikten sonra program tarafından gerçekleştirilen sonlu elemanlar yöntemi analizi ile değerler elde edilmektedir.

\section{Araştırma Sonuçları ve Tartışma}

\subsection{Bulgular}

Çalışmada incelenen alüminyum ve polipropilen balpeteği için B. Ortotropik Malzemelerin Elastiklik Sabitlerinin Sayısal Hesaplanması bölümünde verilen formülleri yardımıyla elastiklik sabitleri hesaplanmıştır. Elde edilen elastiklik modülleri Tablo 2'de, poisson oranı değerleri Tablo 3'te ve kayma modülü değerleri Tablo 4'te verilmiştir.
Tablo 2. Alüminyum ve Polipropilen Balpeteklarinin Sayısal Hesaplanan Elastiklik Modülleri

\begin{tabular}{|c|c|c|c|}
\hline Balpeteği & $\boldsymbol{E}_{\mathbf{1}}[\boldsymbol{M P a}]$ & $\boldsymbol{E}_{\mathbf{2}}[\boldsymbol{M P a}]$ & $\boldsymbol{E}_{\mathbf{3}}[\boldsymbol{M P a}]$ \\
\hline Polipropilen & 0,70 & 0,70 & 63,1 \\
\hline Alüminyum & 0,11 & 0,12 & 610 \\
\hline
\end{tabular}

Tablo 3. Alüminyum ve Polipropilen Balpeteklarinin Sayısal Hesaplanan Poisson Oranlarl

\begin{tabular}{|c|c|c|c|}
\hline Balpeteği & $\boldsymbol{v}_{\mathbf{1 2}}$ & $\boldsymbol{v}_{\mathbf{2 3}}$ & $\boldsymbol{v}_{\mathbf{1 3}}$ \\
\hline Polipropilen & 1 & 0 & 0 \\
\hline Alüminyum & 1 & 0 & 0 \\
\hline
\end{tabular}

Tablo 4. Alüminyum ve Polipropilen Balpeteklarinin Sayısal Hesaplanan Kayma Modülleri

\begin{tabular}{|c|c|c|c|}
\hline Balpeteği & $\boldsymbol{G}_{\mathbf{1 2}}[\mathbf{M P a}]$ & $\boldsymbol{G}_{\mathbf{2 3}}[\mathbf{M P a}]$ & $\boldsymbol{G}_{\mathbf{1 3}}[\mathbf{M P a}]$ \\
\hline Polipropilen & 0,43 & 15,4 & 19 \\
\hline Alüminyum & 0,20 & 132 & 119,2 \\
\hline
\end{tabular}

ANSYS programının Material Design modülü kullanılarak elde edilmiş mühendislik sabitleri, elastiklik modülleri değerleri Tablo 5'te, poisson oranı değerleri Tablo 6'da, kayma modülü değerleri Tablo 7'de bulunmaktadır.

Tablo 5. Alüminyum ve Polipropilen Balpeteklarinin Sonlu Elemanlar Yöntemi ile Hesaplanan Elastiklik Modülleri

\begin{tabular}{|c|c|c|c|}
\hline Balpeteği & $\boldsymbol{E}_{\mathbf{1}}[\mathbf{M P a}]$ & $\boldsymbol{E}_{\mathbf{2}}[\mathbf{M P a}]$ & $\boldsymbol{E}_{\mathbf{3}}[\mathbf{M P a}]$ \\
\hline Polipropilen & 0,87 & 0,87 & 71,4 \\
\hline Alüminyum & 0,12 & 0,12 & 703,2 \\
\hline
\end{tabular}

Tablo 6. Alüminyum ve Polipropilen Balpeteklarinin Sonlu Elemanlar Yöntemi ile Hesaplanan Poisson Oranları

\begin{tabular}{|c|c|c|c|}
\hline Balpeteği & $\boldsymbol{v}_{\mathbf{1 2}}$ & $\boldsymbol{v}_{\mathbf{2 3}}$ & $\boldsymbol{v}_{\mathbf{1 3}}$ \\
\hline Polipropilen & 0,977 & 0,0052 & 0,0052 \\
\hline Alüminyum & 0,999 & 0,0006 & 0,0006 \\
\hline
\end{tabular}

Tablo 7. Alüminyum ve Polipropilen Balpeteklarinin Sonlu Elemanlar Yöntemi ile Hesaplanan Kayma Modülleri

\begin{tabular}{|c|c|c|c|}
\hline Balpeteği & $\boldsymbol{G}_{\mathbf{1 2}}[\mathbf{M P a}]$ & $\boldsymbol{G}_{\mathbf{2 3}}[\mathbf{M P a}]$ & $\boldsymbol{G}_{\mathbf{1 3}}[\mathbf{M P a}]$ \\
\hline Polipropilen & 0,22 & 13,02 & 13,02 \\
\hline Alüminyum & 0,31 & 133 & 133 \\
\hline
\end{tabular}

Sayısal ve Sonlu Elemanlar Yöntemi ile elde edilen balpeteklerinin ortotropik malzeme sabitleri ile balpeteği yapısının sürekli modeli Creo programında oluşturulmuştur. Hazırlanan model ile kompozitin yüzeyi de modellenerek nihai kompozit modellenmesi yapılmıştır. Modellenen her iki kompozit de Şekil 3'te gösterilen treyler ön panelinin 3D modeline uygulanmıştır. 
Elde edilen model, ANSYS programına aktarılarak analiz için bazı komponentler Şekil 5'te gösterildiği şekilde montajdan çıarılmıştır. Static Structual modülünde ön panelin statik analizler gerçekleştirilmiştir.

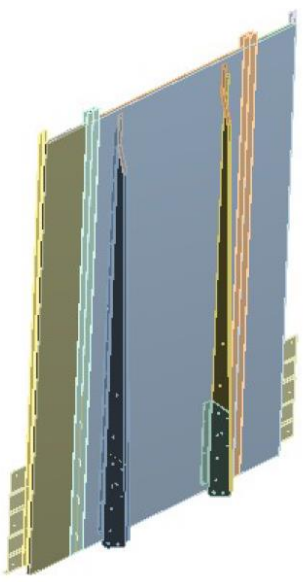

Şekil 5. Ön Panelin FEA İçin Basitleştirilmiş 3D Modeli

Treyler ön panellerini de kapsayan bir regülasyon olan TS EN 12642'de (Türk Standartlar Enstitüsü, 2016) statik yük altındaki dayanım değerleri belirtilmiştir. $\mathrm{Bu}$ regülasyon gereğince toplam yükün, tenteli perdeli araçlar için 30 ton, yarısı panel yüzeyinin $3 / 4$ uygulanması gerekmektedir. Çalışmada TS EN 12642 regülasyonu gereksinimleri göz önüne alınarak analizler geçekleştirilmiştir.

\subsubsection{Gerilme Dağılımı}

Polipropilen balpeteği ve S320 yüzeye sahip kompozitin ön panele uygulanması ile en yüksek gerilme $2439 \mathrm{MPa}$ ile panelin orta kısmında takviye krosu ile bağlanan kısımda meydana gelmiştir. Panelin alt ve orta kısımlarında kompozit levha malzemesinin gerilmesin S320 malzemesinin akma gerilmesine yakın olmasına karşın üst kısımlarında okunan değerin hayli üzerinde olduğu Şekil 5 ve Şekil 6'da görülmektedir.

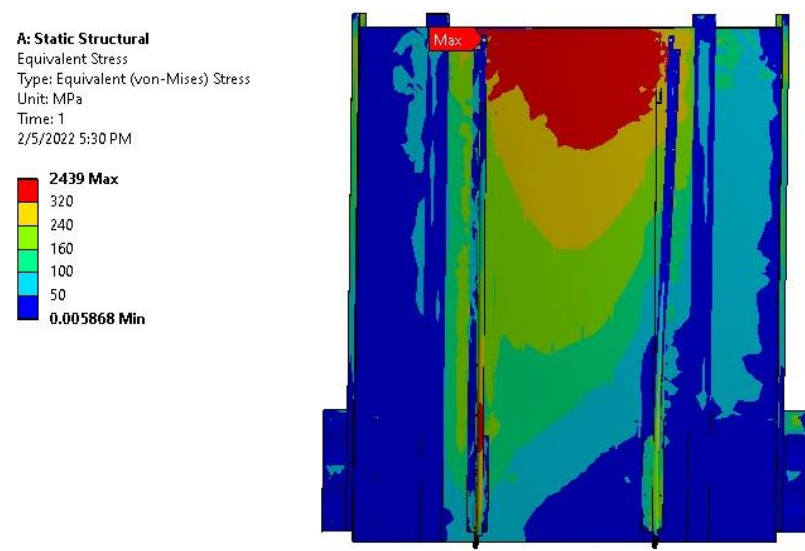

Şekil 6. Polipropilen Balpeteği Kompozit Ön Panel Ön Yüzeyindeki Gerilme Dă̆ılımı

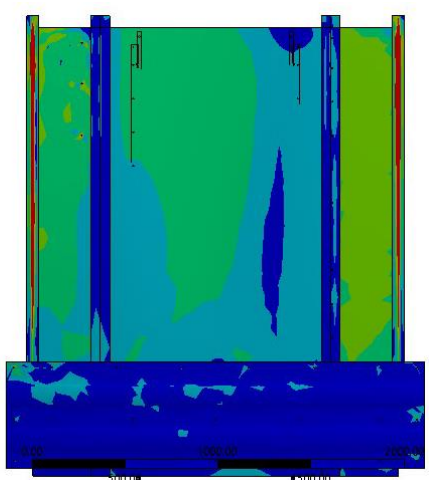

Şekil 7. Polipropilen Balpeteği Kompozit Ön Panel Arka Yüzeyindeki Gerilme Dağılımı

Şekil 8 ve Şekil 9'da gösterilen alüminyum balpeteği kompozit ön panele yapılan analiz ile panel üzerindeki en yüksek gerilme 391,4Mpa ile panelin orta kısmında takviye krosu ile bağlanan kısımda meydana gelmiştir. Panel yüzeyinde stres dağılımı 40 ile $120 \mathrm{MPa}$ arasında değişiklik göstermektedir.

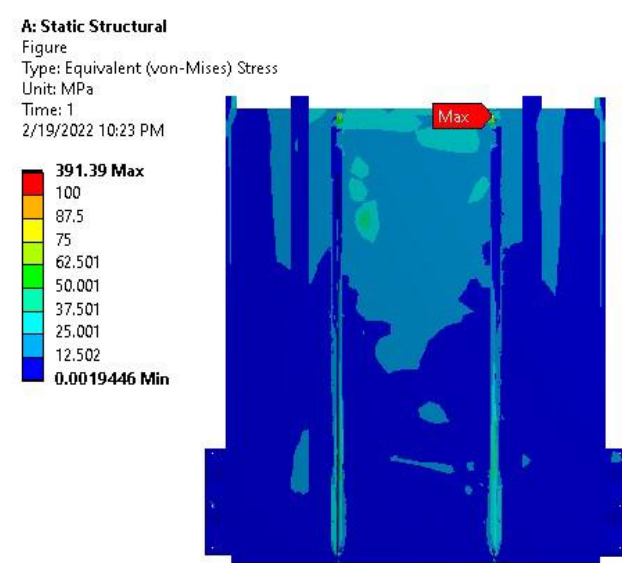

Şekil 8. Alüminyum Balpeteği Kompozit ile Modellenen Ön Paneldeki Arka Yüzeyindeki Gerilim Dă̆ılımı

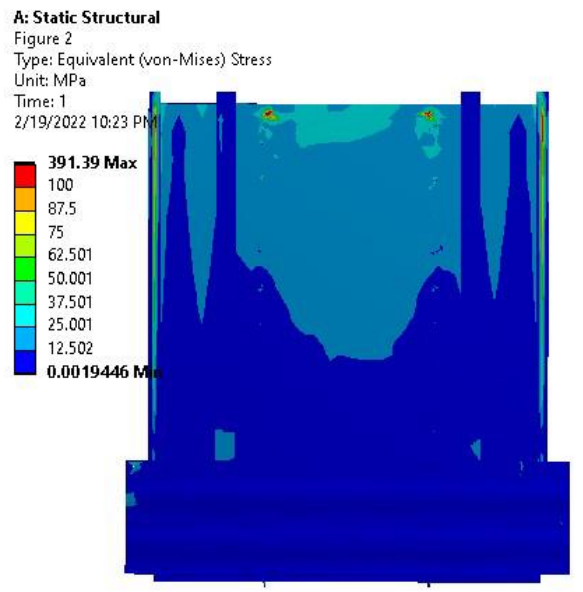

Şekil 9. Alüminyum Balpeteği Kompozit ile Modellenen Ön Paneldeki Ön Yüzeyindeki Gerilim Dă̆ılımı 


\subsubsection{Deplasman Değeri}

Analizin bir diğer çıktısı olarak deplasmana bakılmıștır. Sekil 10 'da polipropilen balpeteği kompozit panelde en yüksek deplasman takviye krosunun üzerinde gözlemlenmiş ve bu değer $68 \mathrm{~mm}$ olarak bulunmuştur.

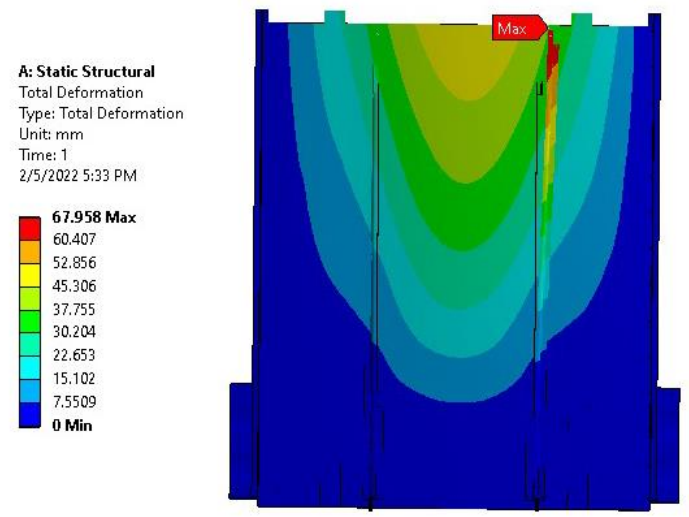

Şekil 10. Polipropilen Balpeteği Kompozit Ön Paneldeki Deplasman Değerleri

Alüminyum balpeteği kompozit ön panelde Şekil 11'de görüldüğü gibi en yüksek deplasman, panelin kritik orta üst kısmında meydana gelmiş olup 29,31 mm değeridir.

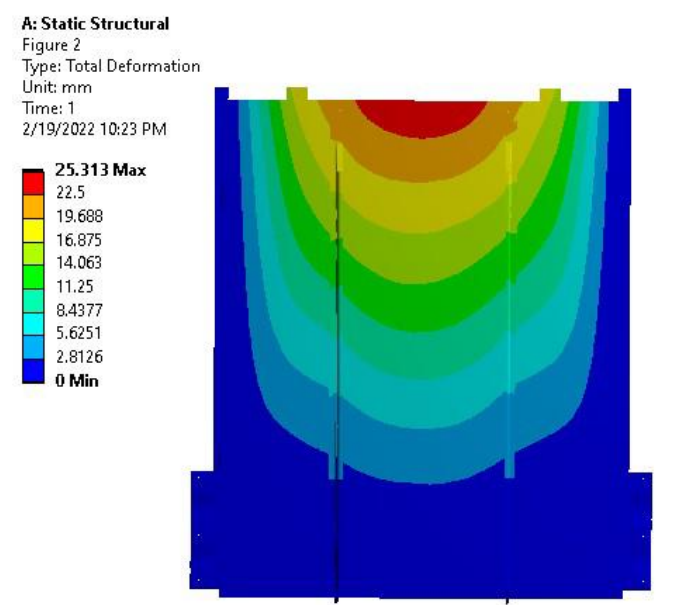

Şekil 11. Alüminyum Balpeteği Kompozit Ön Paneldeki Deplasman Değerleri

\subsubsection{Gerinim Enerjisi}

Analiz sonucunda gerinim enerjisi de çıktı olarak incelenmiş̧tir. Polipropilen balpeteği kompozit ön panelde elde edilen verilerde en yüksek değer olarak $3107.7 \mathrm{~mJ}$ Şekil 12'de gözlemlenmiştir. Panelin kritik olarak değerlendirilen orta üst kısmında ise değer 500 ile $650 \mathrm{~mJ}$ değerlerinde olduğu hesaplanmıştır.

Şekil 13'te gösterilen alüminyum balpeteği kompozite ise en yüksek değer olarak 285,29 mJ gözlemlenmiştir. Panelde depolanan en yüksek enerjinin panelin üst orta kısımda olduğu ve panelin gerilme enerjisinin oldukça düşük olduğu belirlenmiş̧ir.

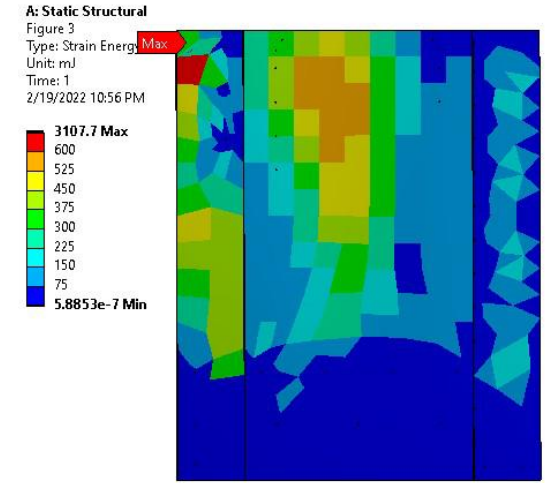

Şekil 12. Polipropilen Balpeteği Kompozit ile Modellenen Ön Paneldeki Gerinim Enerjisi

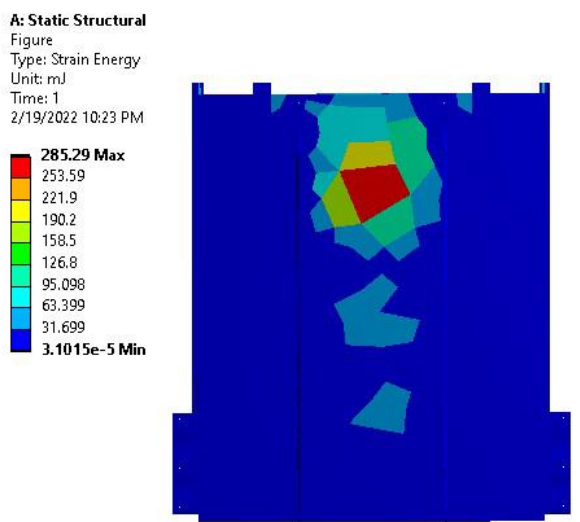

Şekil 13. Alüminyum Balpeteği Kompozit ile Modellenen Ön Paneldeki Gerinim Enerjisi

\subsection{Tartışma}

Sonlu Elemanlar yöntemi ile elde edilen ortotropik malzeme sabitleri verileri ve sayssal hesaplama verileri karşılaştırıldıklarında kendi içerlerinde tutarlılık sağladıkları gözlemlenmiştir. Bu durumda elde edilen verilerin uygulanabilir olduğuna karar verilmiş, yapılan analizlerde sonlu elemanlar yöntemi ile elde edilen veriler ile devam edilmiştir.

Polipropilen balpeteğinin E1 ve E2 yönlerindeki elastiklik modülleri, malzemenin kendi izotropik elastiklik modülü alüminyumdan düşük olmalarına rağmen yüksek çıkmıştır. Bunun başlıca sebebi polipropilen balpeteği kalınlı̆̆ının alüminyuma göre daha yüksek olmasından dolayıdır. E3 G23 ve G13 değerine baktığımızda ise alüminyumun polipropilene karşı üstün olduğu gözükmektedir. Treylerin yapısı ve kompozitlerin konumlandırmalarından kaynaklı olarak yük ve darbe direk olarak 3 yönünden gelmektedir. Alüminyumun 3 yönündeki elastiklik ve kesme sabitlerinin daha yüksek olmasından dolayı alüminyum balpeteği daha uygulanabilir bir yapıya sahip olduğuna kanaat getirilmiştir.

Polipropilen balpeteğine sahip kompozitin uygulandığı ön panelin analizleri incelendiğinde, gerilme değerleri kompozitin yüzeyini oluşturan S320 çeliğinin akma gerilmesi değerlerinin oldukça üzerinde olduğu saptanmıştır, bu durumda kesinlikle panelin üzerinde plastik deformasyon gözlemlenecektir. Elde edilen analiz sonuçlarında deformasyon değerleri en yüksek $68 \mathrm{~mm}$ olarak bulunmuştur. Bu değer her ne kadar TS EN 12642 regülasyonunda verilen deformasyon aralığında olsa dahi gerilme değerlerinde görülen $2500 \mathrm{MPa}$ değerinde deformasyonun bu 
seviyelerde kalamayacağı, daha önce bahsedildiği gibi plastik deformasyonla panelde kırılmanın gerçekleşeceği ön görülmektedir. Panellerin absorbe ettiği gerinim enerjisi incelendiğinde alüminyum balpeteğine göre oldukça yüksek değerler elde edilmiştir.

Alüminyum balpeteği sandviç kompozit ile yapılan ön panelin analiz sonuçlarına bakıldığında elde edilen veriler uygulanabilirlik açısından olumlu olduğu değerlendirilmiştir. Diğer bir değişle, ön panelde yük sonrası oluşan gerilmeler alüminyum balpeteği ve levhalarının dayanım gösterebileceği değerler oldukları ifade edilmiştir. Elde edilen maksimum gerilme değeri, panel ile takviye krosu bağlantısında gerçekleşmektedir. Krosun bağlantı tipi veya krosun kendi yapısında tasarımsal değişiklikler yapılarak bu gerilmenin bölgede dağıtılabileceği ön görülmektedir. Panelin genelinde 10 ile $50 \mathrm{Mpa}$ arasında değişiklik gösterdiğinden gerilme değerleri kullanılan alüminyum plakanın akma gerilmesi değeri altında değerler olduğundan bu yapının uygulanabilir olduğunun bir göstergesidir. Analiz sonucu elde edilen maksimum deformasyona bakıldığında ise oldukça küçük bir değer elde edildiği görülmekte olup TS EN 12462 test değerleri deformasyon aralığında bulunduğundan deformasyon açısından malzemenin panele uygulanabilirliği üzerine bir olumsuzluğu olmadığı saptanmıştır. Panelin gerilme enerjisi değerlerine bakıldığında metal malzemeden üretilen balpeteklerinden beklenildiği üzere enerji absorbe değeri düşük olduğu gözlemlenmiştir.

\section{Sonuç}

İki farklı balpeteği kompozit panellere uygulanan analizler sonucunda; polipropilen balpeteği sandviç kompozitin treyler ön panellerine uygulanabilir olmadığ saptanmıştır. Polipropilen balpetekli kompozitlerin uygulanabilmesi için yüzey ve kompozitin genel kalınlıkları arttırılması gerekmektedir. $\mathrm{Bu}$ durumda, ön panelin treylerin iç kısmına sarkmasından ötürü araç içi hacmin azalmasına, panelin toplam ağırlığında artış gibi dezavantajları oluşturmaktadır.

Alüminyum balpeteği sandviç kompozitlerin treyler ön panellerine dayanıklılıkları ve hafiflikleri sayesinde uygulanabileceği analizlerle ortaya konmuştur.

\section{Teşekkür}

Yazarlar, bu çalışmada vermiş oldukları desteklerinden dolayı Tirsan Treyler San ve Tic. A.Ş.' ye teşekkürlerini sunar.

\section{Kaynakça}

Schellens, H., Peijs, T. Design of A Multi-Functional Semitrailer Using Structural Sandwich Panels, Eindhoven University of Technology, Hollanda.

Karayolları Genel Müdürlüğü, (2022), Karayollari Trafik Yönetmeliği, Erişim adresi https://www.mevzuat.gov.tr/mevzuat?Mevzuat No $=8182 \&$ MevzuatTur=7\&MevzuatTertip $=5$

Tırsan Treyler, Tenteli Perdeli, Erişim adresi https://tirsan.com. tr/perdeli-ve-tenteli-13-c/mega-25-c

Türk Standartlar Enstitüsü, (2016), Karayolu Taşıtlarında Yük Emniyeti-Ticari Araçların Gövde Yapısı-Asgari Gerekler, (TS EN 12642), ICS 43.080.10.

Zinno, A., Prota, A., Di Maio, E., Bakis, C. E., (2011) Experimental Characterization of Phenolic-Impregnated
Honeycomb Sandwichstructures for Transportation Vehicles, Department of Structural Engineering, University of Naples, İtalya.

Gao, X., Zhang, M., Huang, Y., Sang L., Hou, W., (2020) Experimental and Numerical Investigation of Thermoplastic Honeycomb Sandwich Structures Under Bending Loading, School of Automotive Engineering, Dalian University of Technology, Dalian, 116024, Çin.

Galos, J., Sutcliffe, M., Newaz, G., (2016), Design, Fabrication and Testing of Sandwich Panel Decking For Use In Road Freight Trailers, Department of Engineering, University of Cambridge, Journal of Sandwich Structures and Materials, Trumpington Street, Cambridge CB2 1PZ, BK.

Hou, W., Shen, Y., Jiang, K., Wang, C., (2022), Study On Mechanical Properties Of Carbon Fiber Honeycomb Curved Sandwich Structure And Its Application In Engine Hood, School of Automotive Engineering, State Key Laboratory of Structural Analysis for Industrial Equipment, Dalian University of Technology, Dalian 116024, Çin.

Pentour Honeycomb Online Store, Erişim adresi https://www.furrental.com/product/aluminium-honeycombcore/

Made-in-China, Erişim adresi https://cngwit.en.made-inchina.com/product/SXanUxNkYhpW/China-EnvironmentFriendly-Polypropylene-Honeycomb-Core-with-NonWoven-Fabric.html

Andrew, J., Schneider, J., Schiffer, A., Hafeez, F., (2022), Dynamic Crushing of Tailored Honeycombs Realized Via Additive Manufacturing, Department of Mechanical Engineering, Khalifa University of Science and Technology, Abu Dhabi.

Aydıncak, İ., (2007) Investigation of Design and Analyses Principles of Honeycomb Structures, The Graduate School of Natural and Applied Sciences of Middle East Technical University. Türkiye.

Kelsey S., Gellatly R. A., Clark B. W., (1958) The Shear Modulus of Foil Honeycomb Cores, Aircraft Engineering., Vol. 30.

Masters I. G., Evans K. E., (1996), Models for the Elastic Deformationof Honeycombs, Composite Structures, Vol. 35.

Zhang J., Ashby M. F., (1992), The Out-of- Plane Propties of Honeycombs Int. J. Mech. Sci., Vol. 34, No. 6.

Liu Q, Zhao Y., (2007), Effect of Soft Honeycomb Core on Flexural Vibration of Sandwich Panel using Low Order and High Order Shear Deformation Models, Journal of Sandwich Structures and Materials, Vol. 9.

Abd-el-Sayed F., Burgess I.W., Jones R., (1979), A Theoretical Approach to the Deformation of Honeycomb-Based Composite Materials, Composites.

Nast E., (1997), On Honeycomb-Type Core Moduli, AIAA/ASME/AHS Adaptive Structures Forum, Kissimmee, FL, Apr. 7-10. 